\title{
MELHORAMENTO DO TRIGO: $X X$. HERDABILIDADES E CORRELAÇ̃̃ES ENTRE OS COMPONENTES DE PRODUÇÃO EM POPULAÇÕES HÍBRIDAS ENVOLVENDO FONTES DE NANISMO $\left({ }^{1}\right)$
}

\author{
CARLOS EDUARDO DE OLIVEIRA CAMARGO $(2,3)$
}

\section{RESUMO}

Foram estimados os valores da herdabifidade em sentido restrito para a produçāo de grăos, altura das plantas, número de espigas por planta e de grãos por espiga e peso de cem grãos, bem como as correlaçōes entre esses parâmetros através de cruzamentos em forma dialélica entre os cultivares $\mathrm{BH}-1146$, Atlas-66, Tordo e Siete Cerros. Plantas representando os pais, as geraçōes $F_{1}$ e $F_{2}$ e os retrocruzamentos para ambos os pais foram estudadas em um ensaio em blocos ao acaso, com cinco repetições, na Estação Experimental de Hyslop, da Universidade Estadual de Oregon, EUA, em 1978. Os valores da herdabilidade em sentido restrito para altura das plantas foram moderadamente altos para os cruzamentos $\mathrm{BH}-1146 \times$ Atlas-66 $(0,55), \mathrm{BH}-1146 \times$ Siete Cerros $(0,60)$ e Atlas-66 $\times$ Siete Cerros $(0,74)$; moderados para os cruzamentos Atlas- $66 \times$ Tordo $(0,43)$ e Tordo $x$ Siete Cerros $(0,41)$, e baixo para o $\mathrm{BH}-1146 \times$ Tordo $(0,24)$. Foram estima-

(1) Trabalho desenvolvido na Universidade Estadual de Oregon (EUA). Recebido para publicação em 7 de abril de 1988 e aceito em 15 de fevereiro de 1989. nas, SP.

(2) Seção de Arroz e Cereais de Inverno, Instituto Agronómico (IAC), Caixa Postal, 28, 13.001 Campi-

(3) Com bolsa de pesquisa do CNPq. 
dos valores médios da herdabilidade em sentido restrito para número de espigas por planta variando de 0,43 a 0,58 para todos os cruzamentos, com exceção do $\mathrm{BH}-1146 \times$ Atlas-66 e Atlas-66 x Tordo, que apresentaram valores baixos. Para o caráter peso de cem grãos, os índices da herdabilidade foram baixos para todos os cruzamentos, à exceçāo do BH-1146 x Atlas-66 e BH-1146 x Siete Cerros, que foram médios (0,40 e 0,45 respectivamente). Os valores da herdabilidade para produçāo de gräos foram baixos, à exceção dos verificados para os cruzamentos BH-1146 $\times$ Tordo $(0,73) \mathrm{e}$ $\mathrm{BH}-1146 \times$ Siete Cerros $(0,62)$. As correlaçōes fenotipicas entre a produção de grāos e o número de espigas por planta, a altura das plantas, o número de grãos por espiga e o peso de cem grãos foram positivas e altamente significativas (com exceção da correlação produção de grāos e peso de cem grãos para a população $\mathrm{BH}-1146 \times$ Atlas-66, que foi não-significativa). Os resultados sugerem ser possivel selecionar somente plantas de porte semianāo, com elevado potencial produtivo, alto número de grãos por espiga e de espigas por planta e elevado peso de cem grãos, desde que grandes populaçōes segregantes sejam conduzidas para favorecer a identificaçāo dos genótipos desejáveis originários das eventuais recombinaçōes genéticas. Tal procedimento vem sendo adotado na seleção de cultivares de porte semi-anão para o Estado de São Paulo.

Termos de indexação: trigo, porte anão, semi-anāo e alto; produção de grāos.

\section{INTRODUÇÃO}

A produção de grãos em trigo é um caráter complexo com diferentes componentes e condicionado por vários fatores de origem genética e ambiental. Seleção para os componentes da produção, tais como número de espigas por planta e de grãos por espiga e peso do grão, que estão sob controle genético relativamente simples, tem mostrado ser mais eficiente do que seleção para produção de grãos per si (GRAFIUS, 1956).

Para o desenvolvimento de um programa de melhoramento genético eficiente, há necessidade de conhecer a herança e o tipo de ação genética envolvida nos caracteres estudados, bem como a natureza da associação entre si (IBRAHIM, 1983). O sucesso do cruzamento entre os cultivares Norin-10 e Brevor14 foi a grande contribuição da Revolução Verde na Ásia, sendo a base para as seleçōes de linhagens de alta produtividade nas regiōes triticolas de todo o mundo (ATHWAL, 1971).

Altos valores de herdabilidade em sentido restrito para altura da planta de trigo foram obtidos por KRONSTAD \& FOOTE (1964); FONSECA \& PATTERSON (1968); KETATA et al.(1976) e CAMARGO \& OLIVEIRA (1983), indicando a existência de efeitos aditivos na expressāo genética desse caráter. 
A herdabilidade em sentido restrito para produção de grãos, peso do grão, número de espigas por planta e de grāos por espiga têm sido estimados com valores médios a baixos (FONSECA \& PATTERSON, 1968; CAMARGO \& OLIVEIRA, 1983), sugerindo que a seleção para esses caracteres seria efetiva nas últimas gerações segregantes, onde o valor genético da progênie seria mais precisamente determinado.

Correlaçōes fenotipicas positivas e altamente significativas foram obtidas para produção de grãos com altura da planta, número de espigas por planta e de grãos por espiga e peso de cem grãos em cruzamentos envolvendo o cultivar IAC-5, de porte alto, e quatro diferentes fontes genéticas de nanismo (CAMARGO \& OLIVEIRA, 1983).

O presente trabalho visou determinar a herdabilidade dos componentes da produção e da altura da planta, além das suas associaçōes em populaçōes originárias de cruzamentos em forma dialélica envolvendo quatro cultivares de trigo.

\section{MATERIAL E MÉTODOS}

Estudaram-se os cultivares de porte alto $\mathrm{BH}-1146\left(\mathrm{P}_{1}\right)$ e Atlas-66 $\left(\mathrm{P}_{2}\right), \mathrm{o}$ 'Tordo' $\left(P_{3}\right)$, originário da fonte de nanismo Tom Thumb, e 'Siete Cerros' $\left(P_{4}\right)$, oriundo da fonte de nanismo Norin-10 x Brevor 14.

Foram obtidas as sementes $F_{1}$ e $F_{2}$ dos cruzamentos $B H-1146 \times$ Atlas-66 $\left(\mathrm{P}_{1} \times \mathrm{P}_{2}\right)$; $\mathrm{BH}-1146 \times$ Tordo $\left(\mathrm{P}_{1} \times \mathrm{P}_{3}\right) ; \mathrm{BH}-1146 \times$ Siete Cerros $\left(\mathrm{P}_{1} \times \mathrm{P}_{4}\right)$; Atlas-66 $\times$ Tordo $\left(P_{2} \times P_{3}\right)$; Atlas-66 $\times$ Siete Cerros $\left(P_{2} \times P_{4}\right)$ e Tordo $\times$ Siete Cerros $\left(P_{3} \times P_{4}\right)$, como também as sementes $F_{1}$ dos retrocruzamentos para ambos os pais, a saber: $\left(P_{1} \times P_{2}\right) \times P_{1},\left(P_{1} \times P_{2}\right) \times P_{2},\left(P_{1} \times P_{3}\right) \times P_{1},\left(P_{1} \times P_{3}\right) \times P_{3},\left(P_{1} \times\right.$ $\left.P_{4}\right) \times P_{1},\left(P_{1} \times P_{4}\right) \times P_{4},\left(P_{2} \times P_{3}\right) \times P_{2},\left(P_{2} \times P_{3}\right) \times P_{3},\left(P_{2} \times P_{4}\right) \times P_{2},\left(P_{2} \times P_{4}\right) \times$ $P_{4},\left(P_{3} \times P_{4}\right) \times P_{3}$ e $\left(P_{3} \times P_{4}\right) \times P_{4}$.

O ensaio foi instalado em 1978, na Estação Experimental de Hyslop, da Universidade Estadual de Oregon, Corvallis, EUA, em delineamento experimental de blocos ao acaso, com cinco repetiçōes. Cada repetiçāo foi constituída de seis linhas de cada um dos híbridos em geração $F_{2}$ e três linhas de cada híbrido em geração $F_{1}$, de cada retrocruzamento e de cada cultivar empregado como genitor. O espaçamento entre as linhas foi de $0,30 \mathrm{~m}$ e, em cada linha, foram cultivadas doze plantas espaçadas de $0,30 \mathrm{~m}$ uma da outra. A primeira e a última planta de cada linha, bem como a primeira e a última linha de cada bloco, constituiram as bordaduras, plantadas com o cultivar Yamhill.

Coletaram-se os seguintes dados para cada planta: 
Altura da planta - Medida, em centímetros, da superfície do solo até a ponta da espiga do colmo mais alto, excluindo as aristas. espigas férteis.

Espigas por planta - Computando somente o número de colmos com

Produção de grãos - Peso, em gramas, da produção total de grãos de cada planta. planta.

Peso de cem grãos - Peso de cem grãos tomados ao acaso de cada

Grãos por espiga - Calculando através da seguinte fórmula:

$$
\text { Grãos por espiga }=\frac{\text { Produção de grãos por planta } \times 100}{\text { Número de espigas por planta } \times \text { peso de cem grãos }}
$$

Todos os caracteres estudados foram analisados pelo teste $\mathrm{F}$. Para a análise de variância, considerou-se a média de cada genótipo em cada repetição. Os efeitos de geração foram divididos em componentes para detectar diferenças entre e dentro de geraçōes. As estimativas da herdabilidade em sentido restrito (proporção entre a variância genética aditiva e a variância fenotípica) foram calculadas para todos os caracteres em estudo e para todos os cruzamentos pelo método de WARNER (1952), utilizando-se a seguinte fórmula:

$$
h_{\text {nis }}^{2}=\left[2 V_{F_{2}}-\left(V_{\mathrm{RC}_{1}}+V_{\mathrm{RC}_{2}}\right)\right] / N_{\mathrm{F}_{2}}
$$

onde $h_{n s}^{2}=$ valor estimado para a herdabilidade em sentido restrito e $V_{F 2}, V_{R C_{1}}$ e $V_{\mathrm{RC}_{2}}=$ variâncias das geraçōes $F_{2}$ e dos retrocruzamentos. fórmula:

$O$ erro padrão para a $h_{n s}^{2}$ foi obtido pela raiz quadrada da seguinte

$$
V\left(h_{n s}^{2}\right)=2\left\{\left(\left(V_{R C}+V_{R C}\right)^{2} / G L F_{2}\right]+\left(V^{2} \mathrm{RC}_{1} / G L R C_{1}\right)+\left(V^{2} R_{2} / G L R C_{2}\right)\right\} / V^{2} F_{2}
$$

onde $\mathrm{V}\left(\mathrm{h}_{\mathrm{ns}}^{2}=\right.$ variância da herdabilidade em sentido restrito; $V_{\mathrm{RC}_{1}}, V_{\mathrm{RC}_{2}}$ e $V_{\mathrm{F} 2}=$ variâncias dos retrocruzamentos e das geraçōes $F_{2}$, e $\mathrm{GL}_{\mathrm{RC}_{1}}, \mathrm{GL}_{\mathrm{RC}_{2}}$ e $\mathrm{GL}_{\mathrm{F} 2}=$ graus de liberdade associados com as respectivas variâncias.

As correlaçōes fenotípicas, genotipicas e ambientes foram usadas para estimar o grau de associação entre todos os caracteres em estudo para cada população. Como sugerido por FALCONER (1960), as correlaçōes usando dados de $F_{1}$ foram consideradas ambientes, aquelas com dados de $F_{2}$, fenotípicas. As correlaçōes genéticas foram calculadas pela seguinte fórmula:

$$
r_{G}=\left(r_{F}-\sqrt{E}_{x} \sqrt{E}_{y} r_{A}\right) / \sqrt{H_{x}} \sqrt{H}_{y}
$$


onde $r_{F}=$ correlação fenotípica entre os caracteres $x$ e $y ; r_{G}=$ correlação genética entre $x$ e $y ; r_{A}=$ correlação ambiente entre $x$ e $y ; H_{x}$ e $H_{y}=$ herdabilidade em sentido restrito para os caracteres $x$ e y respectivamente, considerando separadamente cada cruzamento; $E_{x}=1-H_{x}, E_{y}=1-H_{y}$.

\section{RESULTADOS E DISCUSSÃO}

As análises de variância para os caracteres estudados encontram-se no quadro 1 e as médias de cada genótipo para cada um desses caracteres, no quadro 2.

Verificou-se que o cultivar Atlas-66 apresentou a maior altura e o 'Tordo', a menor, diferindo ambos dos demais. O cultivar BH-1146 mostrou plantas mais altas que o 'Siete Cerros'. Nas condiçōes do ensaio sem limitação de água e executado em solo alcalino de alta fertilidade, a característica altura da planta se expressou mostrando para os cultivares $\mathrm{BH}-1146$, Siete Cerros e Tordo porte de 139,8,100,7 e 58,3cm respectivamente. Trabalhos desenvolvidos por CAMARGO \& OLIVEIRA (1983) em solos ácidos de Itararé, determinaram a altura das plantas 'Siete Cerros' e 'Tordo' como 68,6 e 47,0cm respectivamente, sendo esses cultivares significativamente diferentes para esse caráter. Em condiçōes de plantio em vasos preenchidos com solo adubado e corrigido e com duas irrigaçōes diárias, localizados no telado contra o ataque de pássaros, em Campinas, verificou-se que o cultivar $\mathrm{BH}-1146$ exibiu um porte de $101,8 \mathrm{~cm}$, significativamente diferente do 'Siete Cerros', com 77,6cm (CAMARGO, 1987). Esses dados demonstram que, em valores absolutos, a altura de planta é bastante influenciada pelo ambiente nos cultivares $\mathrm{BH}-1146$, Siete Cerros e Tordo, sendo pouco influenciada pelo ambiente em valores relativos.

Comparando as médias dentro das populações $F_{1}$ e $F_{2}$, verificou-se que todos os cruzamentos diferem entre si, sendo (BH-1146 $\times$ Atlas-66) o mais alto e (Tordo $x$ Siete Cerros), o mais baixo. Os cruzamentos onde se empregou o cultivar Tordo mostraram as médias mais baixas em relação à altura de planta, confirmando dados indicativos de que os genes encontrados no 'Tordo' exibem dominância parcial para porte baixo (LEON, 1975, e CAMARGO \& OLIVEIRA, 1981). Pelas médias dos $\mathrm{RC}_{1} \mathrm{~s}$, o retrocruzamento (BH-1146 x Atlas-66) x Atlas-66 apresentou as plantas mais altas, diferindo dos demais, com exceção do (Atlas-66 $x$ Siete Cerros) $\times$ Atlas -66 . O retrocruzamento (Tordo $\times$ Siete Cerros) $\times$ Siete Cerros exibiu as plantas mais baixas, diferindo dos demais. Em relação às gerações $\mathrm{RC}_{2}$, o retrocruzamento $(\mathrm{BH}-1146 \times$ Atlas-66) $\times \mathrm{BH}-1146$ apresentou as plantas mais altas e o (Tordo $\times$ Siete Cerros) $\times$ Tordo, as mais baixas, diferindo entre si e dos demais genótipos estudados. 


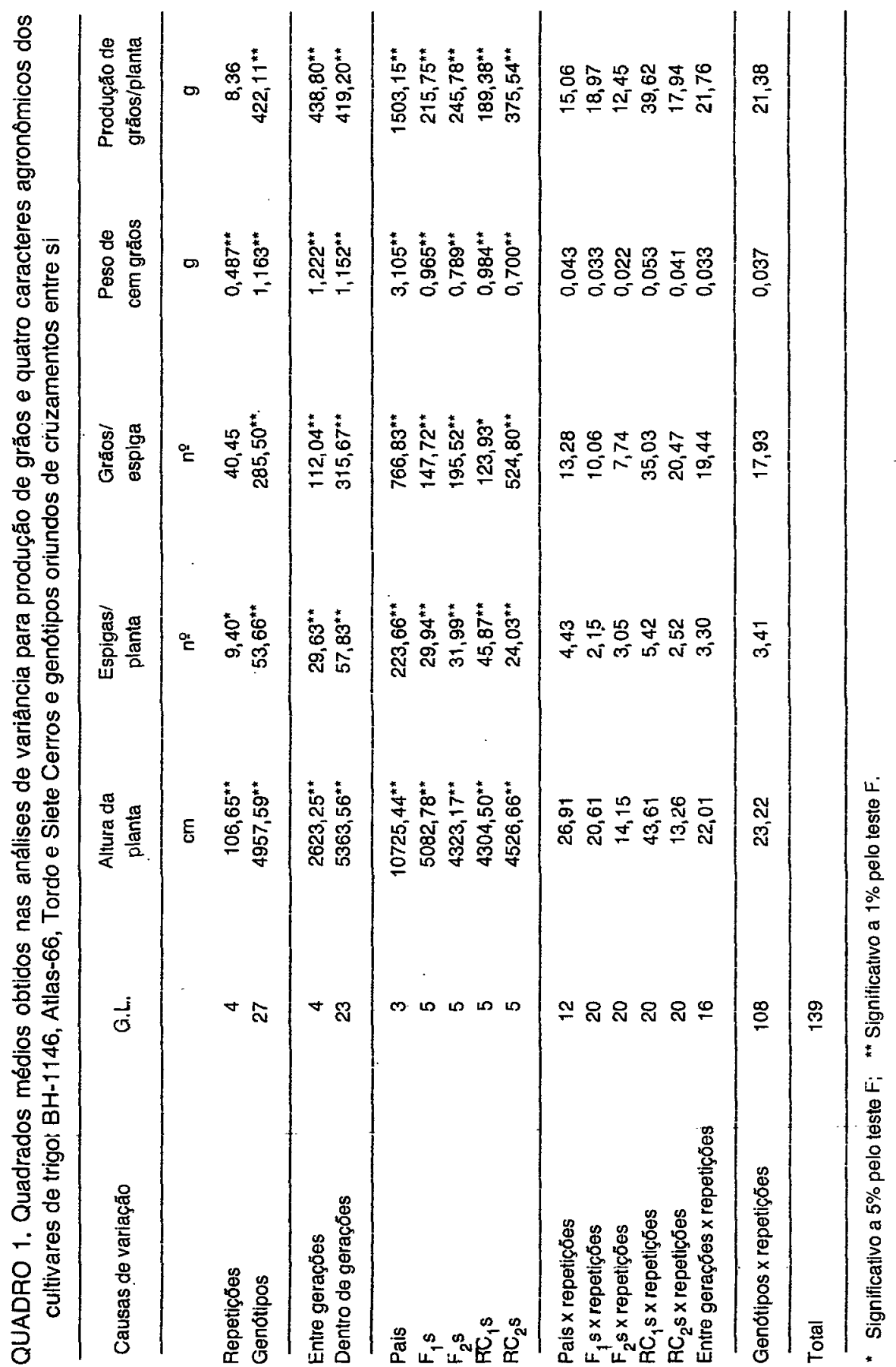


QUADRO 2. Médias e diferenças mínimas significativas dos caracteres agronômicos estudados em cruzamentos em forma dialélica, envolvendo os cultivares $\mathrm{BH}-1146$, Atlas-66, Tordo e Siete Cerros

\begin{tabular}{|c|c|c|c|c|c|}
\hline Genótipos & $\begin{array}{l}\text { Altura da } \\
\text { planta }\end{array}$ & $\begin{array}{l}\text { Espigas/ } \\
\text { planta }\end{array}$ & $\begin{array}{l}\text { Grãos/ } \\
\text { espiga }\end{array}$ & $\begin{array}{l}\text { Peso de } \\
\text { cem grāos }\end{array}$ & $\begin{array}{l}\text { Produção de } \\
\text { grăos/planta }\end{array}$ \\
\hline & $\mathrm{cm}$ & $\mathrm{n}^{0}$ & $n^{\circ}$ & $\mathrm{g}$ & $\mathrm{g}$ \\
\hline $\mathrm{BH}-1146\left(\mathrm{P}_{1}\right)$ & 139,8 & 15,9 & 46,0 & 4,81 & 35,0 \\
\hline Atlas- $66\left(P_{2}\right)$ & 164,0 & 24,6 & 55,0 & 3,94 & 53,2 \\
\hline Tordo $\left(P_{3}\right)$ & 58,3 & 9,0 & 41,1 & 2,89 & 10,9 \\
\hline Siete Cerros $\left(P_{4}\right)$ & 100,7 & 12,5 & 69,3 & 3,91 & 33,7 \\
\hline d.m.s. (5\%) & 9,7 & 4,0 & 6,8 & 0,38 & 7,3 \\
\hline \multirow{7}{*}{$\begin{array}{l}P_{1} \times P_{2}\left(F_{1}\right) \\
P_{1} \times P_{3}\left(F_{1}\right) \\
P_{1} \times P_{4}\left(F_{1}\right) \\
P_{2} \times P_{3}\left(F_{1}\right) \\
P_{2} \times P_{4}\left(F_{1}\right) \\
P_{3} \times P_{4}\left(F_{1}\right) \\
\text { d.m.s. }(5 \%)\end{array}$} & 162,3 & 19,4 & 50,4 & 4,65 & 45,2 \\
\hline & 96,3 & 14,5 & 54,6 & 4,89 & 38,6 \\
\hline & 133,6 & 15,6 & 57,8 & 4,98 & 44,9 \\
\hline & 111,2 & 18,7 & 59,9 & 4,41 & 49,2 \\
\hline & 144,3 & 17,1 & 66,2 & 4,07 & 46,3 \\
\hline & 76,6 & 13,1 & 60,9 & 3,90 & 31,2 \\
\hline & 9,0 & 3,0 & 6,3 & 0,36 & 8,7 \\
\hline \multirow{7}{*}{$\begin{array}{l}P_{1} \times P_{2}\left(F_{2}\right) \\
P_{1} \times P_{3}\left(F_{2}\right) \\
P_{1} \times P_{4}\left(F_{2}\right) \\
P_{2} \times P_{3}\left(F_{2}\right) \\
P_{2} \times P_{4}\left(F_{2}\right) \\
P_{3} \times P_{4}\left(F_{2}\right) \\
\text { d.m.s. }(5 \%)\end{array}$} & 158,7 & 20,1 & 48,4 & 4,50 & 43,6 \\
\hline & 95,3 & 16,0 & 48,5 & 4,40 & 33,5 \\
\hline & 126,5 & 15,5 & 55,0 & 4,75 & 40,2 \\
\hline & 107,5 & 16,4 & 53,5 & 4,05 & 35,3 \\
\hline & 137,7 & 17,7 & 64,4 & 4,01 & 45,6 \\
\hline & 78,3 & 12,4 & 59,3 & 3,64 & 26,8 \\
\hline & 7,5 & 3,5 & 5,5 & 0,30 & 7,0 \\
\hline \multirow{7}{*}{$\begin{array}{l}\left(P_{1} \times P_{2}\right) \times P_{2} \\
\left(P_{1} \times P_{3}\right) \times P_{1} \\
\left(P_{1} \times P_{4}\right) \times P_{1} \\
\left(P_{2} \times P_{3}\right) \times P_{2} \\
\left(P_{2} \times P_{4}\right) \times P_{2} \\
\left(P_{3} \times P_{4}\right) \times P_{4} \\
\text { d.m.s. }(5 \%)\end{array}$} & 161,8 & 21,5 & 51,5 & 4,27 & 47,0 \\
\hline & 117,9 & 15,3 & 49,1 & 4,84 & 36,0 \\
\hline & 135,9 & 16,5 & 48,1 & 4,87 & 38,5 \\
\hline & 134,4 & 20,1 & 57,4 & 4,02 & 46,1 \\
\hline & 156,4 & 19,6 & 57,6 & 4,06 & 45,7 \\
\hline & 80,9 & 13,9 & 60,0 & 3,83 & 32,3 \\
\hline & 13,1 & 4,6 & 11,8 & 0,46 & 12,5 \\
\hline \multirow{7}{*}{$\begin{array}{l}\left(P_{1} \times P_{2}\right) \times P_{1} \\
\left(P_{1} \times P_{3}\right) \times P_{3} \\
\left(P_{1} \times P_{4}\right) \times P_{4} \\
\left(P_{2} \times P_{3}\right) \times P_{3} \\
\left(P_{2} \times P_{4}\right) \times P_{4} \\
\left(P_{3} \times P_{4}\right) \times P_{3} \\
\text { d.m.s. }(5 \%)\end{array}$} & 160,2 & 18,1 & 45,8 & 4,76 & 39,3 \\
\hline & 77,9 & 14,6 & 45,1 & 3,87 & 25,2 \\
\hline & 115,9 & 13,9 & 59,1 & 4,31 & 36,6 \\
\hline & 90,1 & 16,2 & 51,8 & 4,02 & 33,5 \\
\hline & 123,7 & 16,4 & 72,6 & 4,00 & 47,5 \\
\hline & 73,0 & 11,9 & 56,2 & 3,71 & 24,8 \\
\hline & 7,2 & 3,2 & 9,0 & 0,40 & 8,4 \\
\hline
\end{tabular}


O cultivar Atlas-66 foi o que apresentou o maior número de espigas por planta, diferindo estatisticamente dos demais. As populaçōes $F_{1}$, onde um dos genitores foi o 'Atlas-66', apresentaram as maiores médias de número de espigas por planta, não diferindo entre si, porém diferindo das demais. O hibrido ( $\mathrm{BH}-1146$ $x$ Atlas-66) em geração $F_{2}$ apresentou o maior número de espigas por planta, diferindo dos demais, com exceçāo do híbrido (Atlas-66 $\times$ Siete Cerros). Entre os $\mathrm{RC}_{1} \mathrm{~s}$, destacaram-se, quanto ao número de espigas por planta, os híbridos (BH-1146 x Atlas-66) x Atlas-66; (Atlas-66 x Siete Cerros) $\times$ Atlas-66 e (Atlas-66 $\times$ Tordo) $\times$ Atlas-66. Entre os $\mathrm{RC}_{2} \mathrm{~s}$, os híbridos $(\mathrm{BH}-1146 \times$ Atlas-66) $\times \mathrm{BH}-1146$, (Atlas-66 $\times$ Tordo) $\times$ Tordo e (Atlas-66 $\times$ Siete Cerros) $\times$ Siete Cerros foram os que apresentaram os maiores valores desse caráter. Os resultados mostraram que 'Atlas-66' foi eficiente em transmitir o maior número de espigas por planta às suas progênies. Como as atuais variedades de trigo em distribuição em São Paulo apresentam baixo número de espigas por planta, o 'Atlas-66' poderia ser utilizado como fonte desse caráter no programa de melhoramento genético no Estado.

Com relação ao número de grãos por espiga, o 'Siete Cerros' apresentou a maior média, diferindo estatisticamente dos demais. Os cultivares Tordo e $\mathrm{BH}-1146$ mostraram as menores médias, não diferindo entre si, porém diferindo dos demais. Comparando as médias dentro das populaçōes $F_{1}$ e $F_{2}$, os cruzamentos (Atlas-66 x Siete Cerros) e (Tordo $\times$ Siete Cerros) mostraram o maior nú-

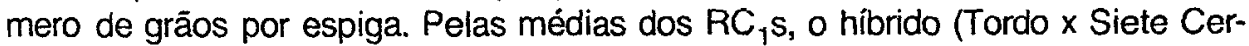
ros) $\times$ Siete Cerros mostrou o maior número de grãos por espiga, somente diferindo, porém, do hibrido ( $\mathrm{BH}-1146 \times$ Siete Cerros) $\times \mathrm{BH}-1146$. Entre os $\mathrm{RC}_{2} \mathrm{~s}$, o hibrido (Atlas-66 $\times$ Siete Cerros) $\times$ Siete Cerros apresentou o maior número de gräos por espiga, diferindo dos demais. Como já visto em trabalhos anteriores (CAMARGO \& OLIVEIRA, 1983, e CAMARGO, 1984a), o cultivar Siete Cerros, em cruzamentos, mostrou-se promissor para transmitir aos descendentes a caracteristica de maior número de grãos por espiga. Nas condiçōes deste experimento, 'Siete Cerros' apresentou a média de 69,3 grãos por espiga e, em Itararé, SP, exibiu 61,9 grãos por espiga (CAMARGO, 1984), sugerindo ser este caráter relativamente pouco influenciado pelo ambiente.

$\mathrm{O}$ ' $\mathrm{BH}-1146$ ' apresentou os grãos mais pesados e o 'Tordo' os mais leves. Ambos diferiram entre si e dos cultivares Siete Cerros e Atlas-66, que não diferiram estatisticamente entre si. Comparando-se as médias dos híbridos em geraçōes $F_{1}$ e $F_{2}$, os cruzamentos (BH-1146 x Attas-66), (BH-1146 $\times$ Tordo) e $(\mathrm{BH}-1146 \times$ Siete Cerros) apresentaram os maiores valores para a caracteristica peso de cem grăos. Entre os $\mathrm{RC}_{1} \mathrm{~s}$, os hibridos (BH-1146 $\times$ Tordo) $\times \mathrm{BH}-1146 \mathrm{e}$ $(\mathrm{BH}-1146 \times$ Siete Cerros) $\times \mathrm{BH}-1146$ foram os que apresentaram os grãos mais pesados, não diferindo entre si, porém diferindo dos demais. Em relação aos $\mathrm{RC}_{2} \mathrm{~s}$, o híbrido ( $\mathrm{BH}-1146 \times$ Atlas-66) $\times \mathrm{BH}-1146$ mostrou a maior média, diferindo dos outros genótipos. Os resultados mostraram que o 'BH-1146' apresentou grande potencial em transferir para suas progênies a característica de maior peso de 
grãos. O 'Tordo', que exibiu 2,89g como peso de cem grãos, em estudos em Itararé, SP, em solo ácido, apresentou a média de $2,88 \mathrm{~g}$, indicando que esse caráter, no cultivar, é pouco dependente das condições de ambiente.

O 'Atlas-66', o mais produtivo, e 'Tordo', o de menor produção de grãos, diferiram entre si e dos cultivares $\mathrm{BH}-1146$ e Siete Cerros, que não diferiram entre si. O cruzamento Atlas-66 $\times$ Tordo, em geração $F_{1}$ - mostrou maior capacidade especifica de combinação: com maior produção de grãos, diferiu estatisticamente somente dos hibridos $\mathrm{BH}-1146 \times$ Tordo e Tordo $\times$ Siete Cerros. Entre os cruzamentos em geração $F_{2}$, destacou-se, quanto à produção de grãos, o híbrido Atlas$66 \times$ Siete Cerros, que somente não diferiu dos hibridos BH-1146 x Atlas-66 e BH$1146 \times$ Siete Cerros. Com relação aos $R C_{1} s$, mostraram as maiores produçōes de grão os híbridos (BH-1146 x Atlas-66) x Atlas-66, (Atlas-66 $\times$ Tordo) $\times$ Atlas-66 e (Atlas-66 x Siete Cerros) $\times$ Atlas-66, que só não diferiram entre si. Entre os $\mathrm{RC}_{2} \mathrm{~s}$, o híbrido (Atlas-66 $\times$ Siete Cerros) $\times$ Siete Cerros foi o mais produtivo, só não diferindo do $(\mathrm{BH}-1146 \times$ Atlas-66) $\times \mathrm{BH}-1146$. O cultivar Atlas-66 apresentou grande potencial produtivo, mostrando-se promissor em transmitir aos descendentes essa característica.

Os valores da herdabilidade em sentido restrito, estimados pelo método de WARNER (1952) para todos os caracteres estudados em cada cruzamento entre os cultivares $\mathrm{BH}-1146$, Atlas-66, Tordo e Siete Cerros, encontram-se no quadro 3.

As herdabilidades em sentido restrito estimadas para o caráter altura da planta foram moderadamente altas para os cruzamentos: $\mathrm{BH}-1146$ x Atlas-66 $(0,55), \mathrm{BH}-1146 \times$ Siete Cerros $(0,60)$ e Atlas-66 x Siete Cerros $(0,74)$. Valores nesses niveis foram também obtidos por FONSECA \& PATTERSON (1968) e KETATA et al. (1976). Para os cruzamentos Atlas-66 $\times$ Tordo e Tordo $\times$ Siete Cerros foram obtidos valores moderados $(0,43$ e 0,41 respectivamente), confirmando JOHNSON et al. (1966) e CAMARGO (1984b). Com exceção do cruzamento BH$1146 \times$ Tordo, onde se obteve um valor baixo $(0,24)$ de herdabilidade em sentido restrito para a altura da planta, os resultados obtidos sugerem que grande parte da variabilidade genética total associada com esse caráter é devida à ação aditiva de genes, indicando que a seleção para esse caráter deve ser efetiva nas primeiras gerações segregantes.

Foram obtidos baixos valores da herdabilidade em sentido restrito para os caracteres: espigas por planta nos cruzamentos $\mathrm{BH}-1146$ x Atlas-66 e Atlas-66 $\times$ Tordo; grãos por espiga nos cruzamentos BH-1146 x Atlas-66 e BH-1146 x Tordo; peso de cem grāos para os cruzamentos BH-1146 x Tordo, Atlas-66 x Tordo, Atlas-66 x Siete Cerros e Tordo $\times$ Siete Cerros; e para produção de grãos para os cruzamentos BH-1146 $\times$ Atlas-66, Atlas-66 $\times$ Tordo, Atlas-66 $\times$ Siete Cerros e Tordo $x$ Siete Cerros. Valores baixos para a herdabilidade em sentido restrito foram obtidos por KETATA et al. (1976) para produção de grãos e número de grãos por espiga; por JOHNSON et al. (1966) para produçāo de grãos e número de espigas 
QUADRO 3. Estimativas da herdabilidade em sentido restrito $\left({ }^{1}\right)\left(H_{n s}\right)$ para todos os caracteres estudados derivados de dados obtidos na base de plantas individuais nas geraçōes $F_{2}^{\prime} s, R C_{1}$ 's e $R C_{2}$ 's para cada cruzamento envolvendo os cultivares $\mathrm{BH}-1146$, Atlas-66, Tordo e Siete Cerros

\begin{tabular}{|c|c|c|c|}
\hline Caráter & $\begin{array}{c}\text { BH- } 1146 \\
x \\
\text { Atlas-66 }\end{array}$ & $\begin{array}{c}\text { BH-1146 } \\
x \\
\text { Tordo }\end{array}$ & $\begin{array}{c}\text { BH-1146 } \\
\times \\
\text { Siete Cerros }\end{array}$ \\
\hline Altura da pianta $(\mathrm{cm})$ & $0,55 \pm 0,16$ & $0,24 \pm 0,21$ & $0,60 \pm 0,16$ \\
\hline Espiga/planta (no) & $0,11 \pm 0,22$ & $0,58 \pm 0,16$ & $0,43 \pm 0,18$ \\
\hline Grāos/espiga (n) & $0,25 \pm 0,20$ & $\dot{0}, 09 \pm 0,22$ & $0,66 \pm 0,16$ \\
\hline Peso de cem grãos $(\mathrm{g})$ & $0,40 \pm 0,18$ & $0,23 \pm 0,21$ & $0,45 \pm 0,18$ \\
\hline Produção de grãos/planta (g) & $0,11 \pm 0,22$ & $0,73 \pm 0,15$ & $0,62 \pm 0,16$ \\
\hline Caráter & $\begin{array}{c}\text { Atlas-66 } \\
\mathrm{x} \\
\text { Tordo }\end{array}$ & $\begin{array}{c}\text { Atlas }-66 \\
\mathrm{x} \\
\text { Siete Cerros }\end{array}$ & $\begin{array}{c}\text { Tordo } \\
\times \\
\text { Siete Cerros }\end{array}$ \\
\hline Altura da planta (cm) & $0,43 \pm 0,19$ & $0,74 \pm 0,15$ & $0,41 \pm 0,19$ \\
\hline Espiga/planta ( ${ }^{\circ}$ ) & $0,10 \pm 0,22$ & $0,43 \pm 0,18$ & $0,48 \pm 0,22$ \\
\hline Grãos/espiga $\left(n^{\circ}\right)$ & $0,31 \pm 0,20$ & $0,39 \pm 0,19$ & $0,41 \pm 0,18$ \\
\hline Peso de cem grãos $(\mathrm{g})$ & $0,16 \pm 0,22$ & $0,18 \pm 0,21$ & $0,12 \pm 0,22$ \\
\hline Produção de grãos/planta (g) & $0,22 \pm 0,21$ & $0,28 \pm 0,20$ & $0,21 \pm 0,21$ \\
\hline
\end{tabular}

(1) Estımada peio método de WARNER (1952).

por planta; e por FONSECA \& PATTERSON (1968) para peso de cem grãos e produção de grãos. Para os cruzamentos que exibiram caracteres com baixos valores da herdabilidade em sentido restrito, a seleção para esses caracteres deve ser feita nas geraçōes mais avançadas quando se espera que o valor genético da progênie seja mais precisamente avaliado.

As correlaçōes fenotipicas e genotípicas entre todos os caracteres estudados para cada cruzamento envolvendo os quatro cultivares, encontram-se no quadro 4.

Os valores das correlações genotípicas calculadas entre a produção de grãos e os demais caracteres concordam com os obtidos para as correlações fenotípicas. Fizeram exceção as correlaçōes genotipicas entre a produção de grãos e a altura da planta para a população BH-1146 x Atlas-66; a produção de grãos e o número de espigas por planta na população Atlas- $66 \times$ Tordo; e a produçãa de grãos e o peso de cem grãos para as populações Atlas-66 $\times$ Siete Cerros e Tordo $x$ Siete Cerros, que foram negativas, quando os valores fenotípicos foram positivos. 
QUADRO 4. Correlaçōes fenotípicas $\left(r_{F}\right)$ e genotípicas $\left(r_{G}\right)$ entre todos os caracteres estudados para cada cruzamento envolvendo os cultivares BH-1146, Atlas-66, Tordo e Siete Cerros

\begin{tabular}{|c|c|c|c|c|}
\hline \multirow[t]{2}{*}{ Caráter } & Espigas/planta & Grāos/espiga & $\begin{array}{l}\text { Peso de cem } \\
\text { gräos }\end{array}$ & $\begin{array}{l}\text { Produçāo de } \\
\text { grãos/planta }\end{array}$ \\
\hline & $r_{G}$ & $r_{G}$ & $r_{F}$ & $\mathrm{I}_{\mathrm{G}}$ \\
\hline
\end{tabular}

EH-1146 x Atlas -66

$\begin{array}{lcccccccrr}\text { Altura da planta } & 0,16 & -0,60 & 0,37^{* *} & >1,00 & -0,01 & -0,10 & 0,26^{* *} & -0,13 \\ \text { Espigas/planta } & & & 0,14^{* *} & >1,00 & -0,18 & -0,87 & 0,89^{* *} & >1,00 \\ \text { Gräos/espiga } & & & & & 0,12 & 0,35 & 0,47^{* *} & >1,00 \\ \text { Peso de cem grãos } & & & & & & & 0,16 & 0,19\end{array}$

BH-1146 x Tordo

\begin{tabular}{|c|c|c|c|c|c|c|c|c|}
\hline Altura da planta & 0,03 & $-0,66$ & $0,21^{*}$ & $>1,00$ & $0,46^{* *}$ & $>1,00$ & $0,26^{* *}$ & 0,05 \\
\hline Espigas/planta & & & $-0,01$ & 0,61 & 0,07 & 0,18 & $0,77^{* *}$ & 0,68 \\
\hline Grāos/espiga & & & & & $0,25^{\star \star}$ & $>1,00$ & $0,46^{\star *}$ & $>1,00$ \\
\hline Peso de cerin grāos & & & & & & & $0,41^{\star *}$ & 0,84 \\
\hline
\end{tabular}

Bi- $-1146 \times$ Siete Cerros

$\begin{array}{lllllllll}\text { Altura da planta } & 0,12 & -0,14 & 0,30^{* *} & 0,54 & 0,27^{* *} & 0,37 & 0,28^{\star *} & 0,23 \\ \text { Espigas/planta } & & & 0,16 & 0,41 & -0,07 & 0,02 & 0,80^{\star *} & 0,76 \\ \text { Grãos/espiga } & & & & & -0,05 & -0,15 & 0,61^{\star *} & 0,83 \\ \text { Peso de cem grãos } & & & & & & & 0,29^{\star *} & 0,46\end{array}$

\begin{tabular}{|c|c|c|c|c|c|c|c|c|}
\hline Altura da planta & 0,06 & $<-1,00$ & $0,44^{* *}$ & $>1,00$ & $0,50^{\star \star}$ & $>1,00$ & $0,48^{\star *}$ & 0,58 \\
\hline Espigas/planta & & & $-0,06$ & 0,59 & 0,05 & 0,74 & $0,58^{\star \star}$ & $<-1,00$ \\
\hline Grãos/espiga & & & & & $0,33^{* *}$ & $>1,00$ & $0,70^{* *}$ & $>1,00$ \\
\hline Peso de cem grãos & & & & & & & $0,48^{* *}$ & $>1,00$ \\
\hline
\end{tabular}

Atlas $-66 \times$ Siete Cerros

$\begin{array}{lllllrrrr}\text { Altura da planta } & 0,31^{* *} & 0,27 & 0,22^{*} & 0,32 & -0,08 & -0,06 & 0,41^{* \star} & 0,89 \\ \text { Espigas/planta } & & & 0,02 & 0,03 & -0,05 & -0,46 & 0,86^{\star \star} & 0,84 \\ \text { Gräos/espiga } & & & & & 0,04 & 0,27 & 0,55^{* \star} & 0,72 \\ \text { Peso de cem gräos } & & & & & & & 0,24^{* *} & -0,25\end{array}$

Tordo $x$ Siete Cerros

$\begin{array}{lcccccccr}\text { Altura da planta } & 0,14 & -0,42 & 0,12 & 0,20 & 0,49^{* *} & 1,00 & 0,45^{* *} & 0,11 \\ \text { Espigas/planta } & & & -0,17 & 0,03 & -0,14 & -0,95 & 0,76^{\star *} & 0,66 \\ \text { Grãos/espiga } & & & & & 0,26^{* *} & 0,64 & 0,36^{* *} & >1,00 \\ \text { Peso de cem grãos } & & & & & & & 0,25^{\star \star} & -0,58\end{array}$

* Correlaçōes fenotipicas significativas ao nivel de $5 \% .{ }^{\star \star}$ Correlaçōes fenotípicas significativas ao nível de $1 \%$. 
Nas populaçōes estudadas, as plantas mais produtivas correlacionaram altamente com plantas de porte alto, com maior número de espigas por planta e de grãos por espiga e com maior peso de cem grãos. Somente na população $\mathrm{BH}-1146$ x Atlas-66, não ocorreu correlação significativa entre as plantas mais produtivas com as de maior peso de cem grãos. Plantas de porte alto foram associadas significativamente com maior número de espigas por planta somente na população Atlas-66 x Tordo, com maior número de grāos por espiga (com exceção da população Tordo $x$ Siete Cerros) e com maior peso de cem grãos (com exceção das populaçōes BH-1146 x Atlas-66 e Atlas-66 x Siete Cerros). Plantas com maior número de espigas não correlacionaram significativamente com maior número de grãos por espiga (com exceção da população $\mathrm{BH}-1146 \times$ Atlas-66) e com maior peso de cem gräos. Plantas com maior número de grãos por espiga correlacionaram altamente com maior peso de cem grãos, somente nas populações BH-1146 x Tordo, Atlas-66 x Tordo e Tordo x Siete Cerros. Resultados semelhantes foram obtidos por JOHNSON et al. (1966), pesquisando as progênies do cruzamento $\epsilon$ ntre dois cultivares de trigo, e por CAMARGO \& OLIVEIRA (1981), estudando as populaçōes provenientes dos cruzamentos entre um cultivar de porte alto e três diferentes fontes de nanismo, em ensaios conduzidos em condição de campo, em ltararé.

Como o programa de melhoramento de trigo visa obter genótipos produtivos, de porte intermediário, nem tão altos e sensiveis ao acamamento como os encontrados nos cultivares $\mathrm{BH}-1146$ e Atlas-66, nem tāo baixos como a fonte de nanismo Tordo, com alto número de grãos por espiga e de espigas por planta e de elevado peso de cem grãos, verificou-se a possibilidade de selecionar plantas com altura média associada com alto potencial de produção e com melhores características agronômicas do que as dos genitores utilizados nos cruzamentos em estudo. Devido à tendência da associação entre altura da planta com produção de grãos e com os demais caracteres agronômicos desejáveis, sugere-se desenvolver grandes populaçōes segregantes para favorecer a identificação dos recombinantes desejáveis.

\section{SUMMARY}

WHEAT BREEDING:

$X X$. HERITABILITIES AND CORRELATIONS AMONG YIELD COMPONENTS IN HYBRID POPULATIONS INVOLVING DIFFERENT SOURCES OF DWARF!SM

Diallelic crosses were made involving the standard height cultivars $\mathrm{BH}-1146$ and Atlas-66, the semidwarf cultivar Siete Cerros and the dwarf source Tordo. Parents, $F_{1}$ 's, $F_{2}$ 's and reciprocal backcrosses were tested for grain yield, plant height, number of heads per plant, number of kernels per head, and for weight of 100 kernels, in an experiment carried out at 
Hyslop Farm, Oregon, U.S.A., in1978. Narrow sense heritability estimates for plant height were moderately high for the crosses $\mathrm{BH}-1146 \times$ Atlas-66 (0.55), $\mathrm{BH}-1146 \times$ Siete Cerros $(0.60)$ and Atlas $-66 \times$ Siete Cerros (0.74), moderate for the crosses Atlas-66 $\times$ Tordo (0.43) and Tordo $\times$ Siete Cerros (0.41) and low for the cross $\mathrm{BH}-1146 \times$ Tordo (0.24). Moderate values $(0.43$ to 0.58 ) were estimated for number of heads per plant for all crosses with exception of the crosses $\mathrm{BH}-1146 \times$ Atlas -66 and Atlas-66 $\times$ Tordo which presented low values for the narrow sense heritability. The heritability values for weight of 100 grains were low for all crosses with exception of the crosses BH-1146 $x$ Atlas -66 and $\mathrm{BH}-1146$ x Siete Cerros which presented moderate levels $(0.40$ and 0.45 , respectively). In relation to grain yield the narrow sense heritability estimates were low with exception of those for the crosses $\mathrm{BH}-1146 \mathrm{x}$ Tordo (0.73) and $\mathrm{BH}-1146 \times$ Siete Cerros (0.62). The phenotypic correlations between grain yield and number of heads per plant, plant height, number of grains per head and weight of 100 grains were positive and mostly highly significant, except for the correlation between grain yield and weight of 100 grains for the population $\mathrm{BH}-1146 \times$ Atlas -66 , which was not significant. The results suggested that it would be possible to select semidwarf plants, with high yield potential ${ }_{\text {, }}$ with higt number of kernels per head and heads per plant, and 100 kernel weight if large segregating populations are used to identify desired genotypes originated from eventual genetic recombinations. This procedure is being used for selections of semidwart wheat cultivars in the State of Sāo Paulo, Brazil.

Index terms: wheat, dwarf, semidwarf and tall types; grain yield.

\section{REFERÊNCIAS BIBLIOGRÁFICAS}

ATHWAL, D.S. Semidwarf rice and wheat in global food needs. Quarterly Review of Biology, 46:1-34, 1971.

CAMARGO, C.E.O. Melhoramento do trigo. VIII. Associaçōes entre produção de grãos e outros caracteres agronômicos em populaçōes híbridas envolvendo diferentes fontes de nanismo. Bragantia, Campinas, 43(2):541-552, $1984 \mathrm{a}$.

. Melhoramento do trigo. X. Estimativas da herdabilidade e correlaçōes entre tolerância à toxicidade de alumínio e produção de grãos com outros caracteres agronômicos em trigo. Bragantia, Campinas, 43(2):615-628, 1984b.

Melhoramento do trigo. XIV. Correlaçōes entre tolerância à toxicidade a dois niveis de alumínio e altura das plantas com outros caracteres agronômicos em trigo. Bragantia, Campinas, 46(1):91-103, 1987.

\& OLIVEIRA, O.F. Melhoramento do trigo. II. Estudo genético de fontes de nanismo para a cultura do trigo. Bragantia, Campinas, 40:77-91, 1981.

\& - Melhoramento do trigo. V. Estimativas da herdabilidade e correlaçóes entre altura, produção de grãos e outros caracteres agronômicos em trigo. Bragantia, Campinas, 42:131-148, 1983.

FALCONER, D.S. Introduction to quantitative genetics. New York, Ronald Press, 1960. $365 p$. 
FONSECA, S. \& PATTERSON, F.L. Yield components heritabilities and interelationships in winter wheat (Triticum aestivum L.). Crop Science, 8:614-617, 1968.

GRAFIUS, J.E. Components of yield in oats: geometrical interpretation. Agronomy Journal, 48:419-423, 1956.

IBPIAHIM, O.E.; OHM, H.W.; NYQUIST, W.E. \& CANTRELL, R.P. Inheritance of kernel number per spikelet and its association with kernel weight in two winter wheat crosses. Crop Science, 28:927-931, 1983.

JOHNSON, V.A.; BIEVER, K.J.; HAUNOLD, A. \& SCHMIDT, J.N. Inheritance of plant height, yield of grain, and other plant and seed characteristics in a cross of hard red winter wheat (Triticum aestivum L.). Crop Science, 6:336-338, 1966.

KETATA, H.; EDWARDS, L.H. \& SMITH, E.L. Inheritance of eight agronomic characters in a winter wheat. Crop Science, 16:19-22, 1976.

KRONSTAD, W.E. \& FOOTE, W.H. General and specific combining ability estimates in winter wheat (Triticum aestivum Vill., Host). Crop Science, 4:616-619, 1964.

LEON, J.L.M. Combining ability of agronomic traits involving three sources of dwarfism in wheat (Triticum aestivum L. en Thell). Oregon State University, 1975. 116fls. Thesis (Ph.D.)

WARNER, J.N. A method for estimating heritability. Agronomy Journal, 7:427-430, 1952. 